\title{
Simulation of Storm Surges in the South Central Coast of Vietnam Under Climate Change
}

\author{
Anh Huy Hoang ${ }^{1^{*}} \quad$ Van Dai Hoang ${ }^{2 *} \quad$ Kim Lien Mai $^{3} \quad$ Tien Thanh Nguyen ${ }^{4 *}$ \\ 1.Faculty of Environment, Hanoi University of Natural Resources and Environment, No. 41A Phu Dien, Bac Tu \\ Liem, Hanoi 100000, Vietnam \\ 2.Centre for HydroMet and Climate change Consultancy, Vietnam Institute of Meteorology, Hydrology and \\ Environment, 23/62 Nguyen Chi Thanh, Dong Da, Hanoi 100000, Vietnam \\ 3.Department of Climate Change, Ministry of Natural Resources and Environment, No. 10 Ton That Thuyet, \\ Cau Giay, Hanoi 100000, Viet Nam \\ 4.Faculty of Surveying, Mapping and Geographic Information, Hanoi University of Natural Resources and \\ Environment, No. 41A Phu Dien, Bac Tu Liem, Hanoi 100000, Vietnam
}

The research was supported by National Research Project Program of Vietnam: science and technology in response to climate change, natural resources and environmental management in the 2016-2020 period (program number: BĐKH/16-20), Developing a sustainable socio-economic model adapting to extreme natural disasters under climate change in the South Central region of Viet Nam. A case study of Ninh Thuan province (grant number: BĐKH.04/16-20).

\section{Abstract}

This paper presents the results of storm surge simulation in the South Central region of Vietnam using the Mike 21-FM HD model. Wind pressure fields of typical storms were first identified in period of 1986-2005 using the parametric wind field model. Storm surge risk was then simulated based on the rare 10, 50 and 100-year frequency corresponding to 2030, 2050, and 2100 scenarios. Storm surge model was finally calibrated and validated using the level of water measured in the November 2009 Typhoon Mirinae and October 2013 Typhoon Nari. The results show that storm surges were consistent with water level variation and amplitude; the maximum and minimum storm surges were $2.34 \mathrm{~m}$ in the Binh Thuan coastal area and $0.78 \mathrm{~m}$ in the Khanh Hoa coastal area, respectively. The results of this study demonstrated the use of MIKE 21-FM HD model for the simulation of storm surges in the future plays an important role in damage risk reduction caused by storm surges.

Keywords: storm surge simulation, climate change, Mike 21-FM HD model, South Central coast of Vietnam.

DOI: $10.7176 / \mathrm{JEES} / 9-6-08$

Publication date:June $30^{\text {th }} 2019$

\section{Introduction}

Storm surges, or conversely sea level depressions are atmospherically forced oscillation of the water level in a coastal or inland water body (Karim \& Mimura, 2008). The surges are generated mainly by wind stresses and, to a lesser extent, falling atmospheric pressure that produces a rise in water level at the rate of approximately $1 \mathrm{~cm} / \mathrm{hPa}$ fall in pressure (McInnes et al, 2002). Storm surges refer to the rise in sea level that may accompany severe storms and may result from both tropical and extratropical storms. A storm surge is a huge mass of water, tens to hundreds $\mathrm{km}$ wide, that sweeps across the coastline where a hurricane makes landfall. The peak storm surge level can reach more than $3 \mathrm{~m}$. The surge of high water topped by waves can be devastating. Along the coast, storm surges are the greatest threat to life and property (Sheng et al, 2010). It is therefore the accurate simulation of storm surge is essential for developing cost effective storm mitigation and preparation.

A number of numerical models have been proposed to simulate storm surges such as MIKE (Li et al, 2017; Pan \& Liu, 2015; Yan et al, 2016), FVCOM (Guo et al, 2009), ADCIRC+SWAN (Musinguzi et al, 2019; Sheng et al, 2010), SLOSH (Houston et al, 1999), SuWAT (Jiang et al, 2016) in coastal areas (Bode \& Hardy, 1997; Casulli \& Cheng, 1992; Sheng et al, 2006). Among these models, MIKE 21- Flexible Mesh (FM) Hydrodynamic (HD) model developed by Danish Hydraulic Institute is a well-documented, proven modelling technology that has been successfully applied in many recent studies (Afentoulis et al, 2017; Bruneau et al, 2017; Hu et al, 2019; Patro et al, 2009). It is therefore MIKE 21- FM HD model was used to simulate storm surges in this study.

When simulation of storm surge, wave, currents, and inundation in the Outer Banks and Chesapeake Bay, Sheng et al (2010) indicated that the accuracy of storm surge simulations depends on many factors such as input data (e.g., bathymetry, topography, and wind/pressure fields), representation of important processes (e.g., flooding and drying, bottom friction, and effects of wave and tide), model grid resolution, and open boundary conditions. For example, Houston et al (1999) compared surface wind observations analysed by the Hurricane Research Division (HRD) to those computed by the parametric wind model used in the National Weather Service Sea, Lake, and Overland Surges from Hurricanes (SLOSH) model's storm surge computations for seven cases in five recent hurricane. Hubbert \& Mclnnes (1999) developed a high resolution storm surge inundation model to model coastal flooding due to storm surges which features a nesting capability and inundation algorithm. Sheng et al 
(2006) proposed a high-resolution unstructured grid model to simulate storm tide in the Chesapeake Bay. In that study, the application of an unstructured grid in the Bay offers the greatest flexibilities in representing complex estuarine geometry near the coast and encompassing a large modelling domain necessary for storm surge simulation. Later, Sheng et al (2010) simulated storm surge, wave, and coastal inundation in the Northeastern Gulf of Mexico region during Hurricane Ivan in 2004. When conducting numerical model experiments to address the previously unexplained anomalously high storm surge along the Florida coast of Apalachee Bay during Hurricane Dennis, Morey et al (2006) indicated that it is important to use a large model domain to incorporate the effect of remote forcing contribution to storm surge. In addition, when simulating storm surges in the Bay of Bengal using one-way coupling between NMM-WRF and IITD storm surge model, Pattanayak et al (2016) suggested using simulated surface meteorological fields of a high-resolution mesoscale model, the storm surge can be predicted at least 2 days in advance of the actual landfall of tropical cyclones with reasonable accuracy. Most recently, Mohit et al (2018) assesses the impact of a major river basin in Bangladesh on storm surge simulation. It can be seen from the above discussion that previous studies on storm surge simulations were quite diverse in simulating storm surge by taking account on main factors, and therefore to assess the level of flooding areas. However, most these studies were limited to the effects of climate change causing sea level rise. It is therefore, in this study, this limitation will be considered by taking account on hypothetical storm tide scenarios to the future mean sea level when simulating storm surges.

\section{Study area and data used}

2.1 Study area

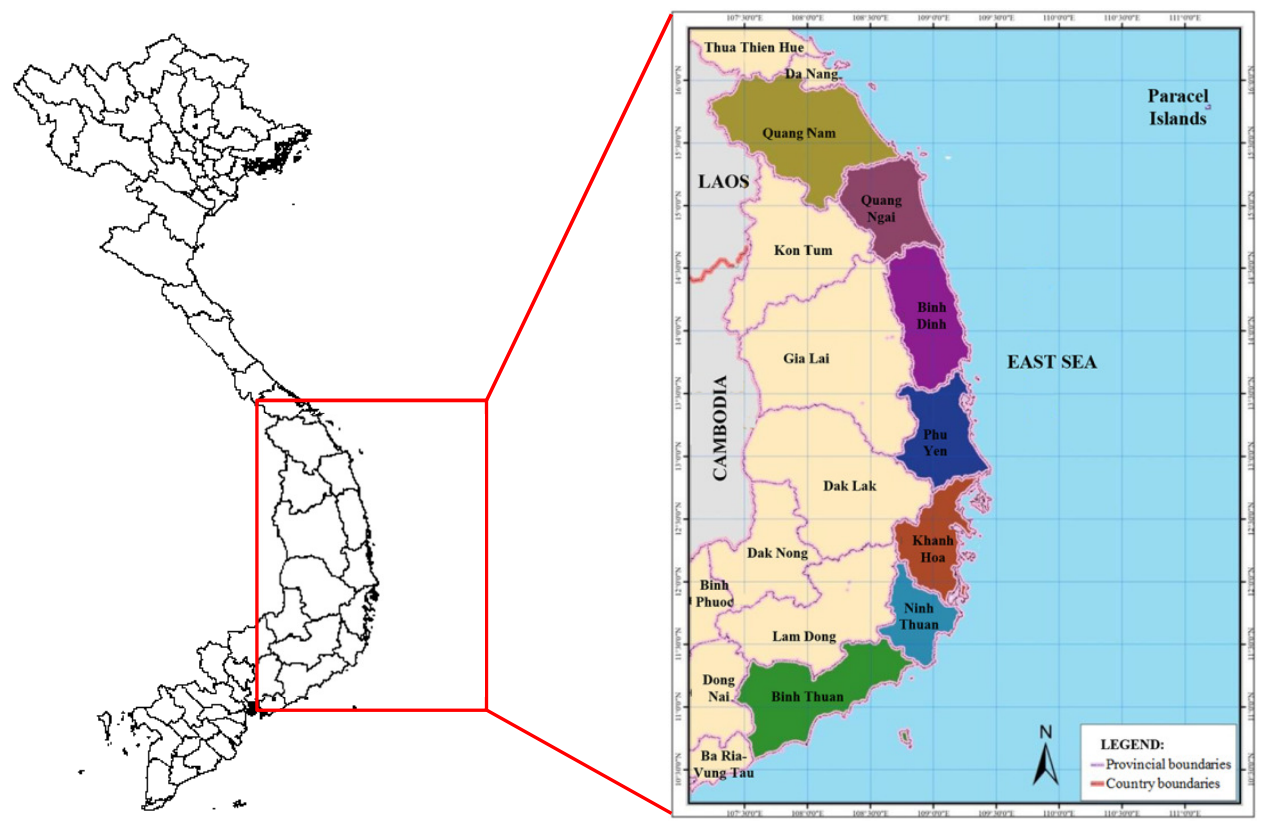

Figure 1. Study area of the South Central region (right) of Viet Nam (left).

The study area is located in the South Central provinces of Vietnam including Da Nang, Binh Dinh, Phu Yen, Khanh Hoa, Ninh Thuan and Binh Thuan. Its geographic location extends latitudinally from $10^{\circ} 33^{\prime} \mathrm{N}$ to $13^{\circ} 40^{\prime} \mathrm{N}$ and longitudinally from $105^{\circ} 44^{\prime} 38^{\prime \prime} \mathrm{E}$ to $106^{\circ} 47^{\prime} 21^{\prime \prime} \mathrm{E}$ (Figure 1). Due to the low-lying topography in the study area (Schmidt-Thome et al, 2015), natural disasters such as storm events tend to increase in frequency and strength (Neumann et al, 2015) make the region susceptible to flooding from storm surges (Imamura \& Van To, 1997; Nguyen et al, 2007; Schmitt et al, 2013; Takagi et al, 2012; Takagi et al, 2014; Thai et al, 2018).

\subsection{Data used}

Digital elevation model data, the wind and pressure fields of the storm were used as a primary input data for storm surge simulation. In this study, based on the new information for each storm, wind fields used as forcing were generated using the parametric model proposed by Young \& Sobey (1981). The past wind pressure fields were reproduced to simulate storm surges for the baseline scenario and to build future scenarios in storm surge risk simulation. The parameters were used to simulate the wind pressure field include storm center position, maximum wind radius, maximum wind speed, storm center pressure, atmospheric pressure.

\section{Method of simulation}

According to Young \& Sobey (1981), the wind speed and pressure components are calculated according to the 
following formulas:

$$
\begin{gathered}
V_{r}=V_{\text {max }}\left(\frac{R}{V_{m}}\right)^{\prime} \exp \left(7\left(1-\frac{R}{V_{m}}\right)\right) \\
V_{r}=V_{\text {max }} \exp \left(\left(0.00257 R_{m}+0.05\right)\left(1-\frac{R}{V_{m}}\right)\right) \\
V_{t}=-0.5 V_{f}(-\cos \varphi) \\
V=V_{r}+V_{t} \\
P=P_{c}+\left(P_{n}-P_{c}\right) \exp \left(-\frac{R}{V_{m}}\right)
\end{gathered}
$$

where $R_{m}$ is the radius to maximum winds, $V_{\max }$ is the maximum wind speed, $P_{c}$ is the central pressure, $P_{n}$ is the neutral pressure, $\varphi$ is the angle between the radial arm and the line of maximum winds, $V_{f}$ is the forward speed. The wind field consists of a rotational and a translational component. At a distance, $R$, from the centre of the cyclone, $V_{r}$ is the rotational wind speed and $V_{t}$ is the translational wind speed.

There is no detailed scenario of storms and tropical depressions in the future, therefore, storm data in period of 1945-2017 has been used to produce hypothetical storm data to build the Weibull probability distribution function. Based on these types of data, thereby calculating the maximum wind velocity and pressure at the center of storms corresponding to the rare frequency. In this study, the rare frequency distribution of storms corresponding to repeating frequencies of 10,50 and 100 years were calculated. In particular, the 10-year frequency corresponds to the level of simple irrigation systems (greater than level IV), 50-year frequency corresponding to IV-level irrigation systems and 100-year frequency corresponding to II-level irrigation systems, corresponding to grade-II irrigation works (according to the National Technical Regulation for irrigation systems of Vietnam). The calculation results were summarised in Table 1.
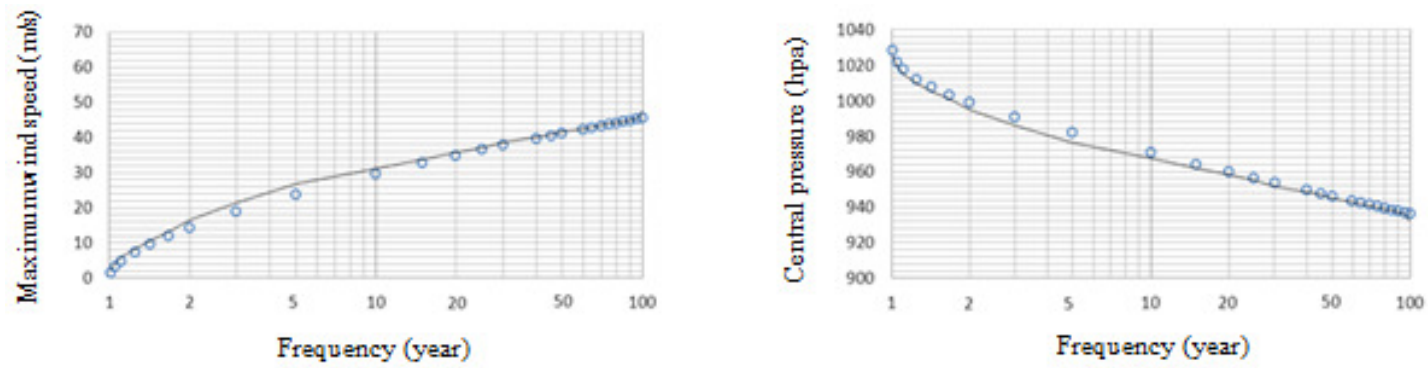

Figure 2. Distribution of maximum wind speed (left) and central pressure (right).

Table 1 . The probability of parameters on each time interval.

\begin{tabular}{|l|c|c|c|}
\hline \multirow{2}{*}{$\begin{array}{c}\text { Time } \\
\text { Parameters }\end{array}$} & \multicolumn{3}{|c|}{ Probability (P) } \\
\cline { 2 - 4 } & 10 -year & 50 -year & 100-year \\
\hline$V_{\max }(\mathrm{m} / \mathrm{s})$ & 30 & 41 & 45 \\
\hline$P_{\min }(\mathrm{hpa})$ & 970 & 946 & 936 \\
\hline
\end{tabular}

With the support of MIKE 21- FM HD model, a tidal current field model is established through the numerical integration of horizontal momentum equation and continuity equation based on the two-dimensional shallow water equations (Wang et al, 2016). The two horizontal momentum equations for the $\mathrm{x}$ - and $\mathrm{y}$-component, and the local continuity equation are expressed by the following equations:

$$
\begin{gathered}
\frac{\partial h}{\partial t}+\frac{\partial h \bar{u}}{\partial x}+\frac{\partial h \bar{v}}{\partial y}=h S \\
\frac{\partial h \bar{u}}{\partial t}+\frac{\partial h \bar{u}^{2}}{\partial x}+\frac{\partial h \overline{v u}}{\partial y}=f \bar{v} h-g h \frac{\partial \eta}{\partial x}-\frac{g h^{2}}{2 \rho_{0}} \frac{\partial \rho}{\partial x}+\frac{\tau_{s x}}{\rho}-\frac{\tau_{b x}}{\rho} \\
-\frac{1}{\rho_{0}}\left(\frac{\partial S_{x x}}{\partial x}+\frac{\partial S_{x y}}{\partial y}\right)+\frac{\partial}{\partial x}\left(h T_{x x}\right)+\frac{\partial}{\partial y}\left(h T_{x y}\right)+h u_{S} S \\
\frac{\partial h \bar{v}}{\partial t}+\frac{\partial h \overline{u v}}{\partial x}+\frac{\partial h \bar{v}^{2}}{\partial y}=-f \bar{u} h-g h \frac{\partial \eta}{\partial y}-\frac{g h^{2}}{2 \rho_{0}} \frac{\partial \rho}{\partial y}+\frac{\tau_{s y}}{\rho}-\frac{\tau_{b y}}{\rho} \\
-\frac{1}{\rho_{0}}\left(\frac{\partial S_{y x}}{\partial x}+\frac{\partial S_{y y}}{\partial y}\right)+\frac{\partial}{\partial x}\left(h T_{x y}\right)+\frac{\partial}{\partial y}\left(h T_{y y}\right)+h v_{S} S
\end{gathered}
$$

where $t$ is the time; $x$ and $y$ are the Cartesian co-ordinates; $h=\eta+d$ is the total water depth; $d$ is the still water depth; $h$ is the surface elevation; $\bar{u}$ and $\bar{v}$ are the velocity components in the $x$ and $y$ direction; $f=2 \Omega \sin (\Phi)$ is the 
Coriolis parameter ( $\Omega$ is the angular rate of revolution and $\Phi$ is the geographic latitude); $g$ is the gravitational acceleration; $\rho$ is the density of water; $v_{t}$ is the vertical turbulent (or eddy) viscosity; $p_{a}$ is the atmospheric pressure; $\rho_{0}$ is the reference density of water; $s$ is the magnitude of the discharge due to point sources; $u_{s}$ and $v_{s}$ are the velocity components by which the water is discharged into the ambient water; $s_{x x}, s_{x y}, s_{y x}$ and $s_{y y}$ are components of the radiation stress tensor; $T_{x x}, T_{x y}, T_{y x}$ and $T_{y y}$ are components of viscous force; $\tau_{s x}$ and $\tau_{s y}$ are the $x$ and $y$ components of the surface wind; $\tau_{b x}$ and $\tau_{b y}$ are the $x$ and $y$ components of the bottom stress.

\section{Model set-up, calibration and validation}

\subsection{Model set-up}

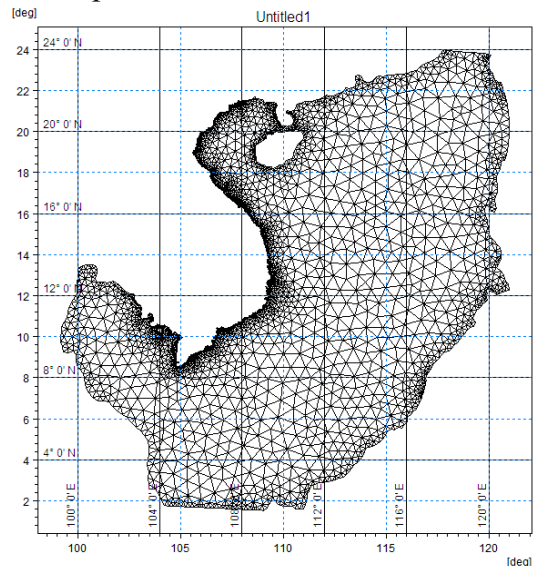

a. Unstructured grid in East Sea.

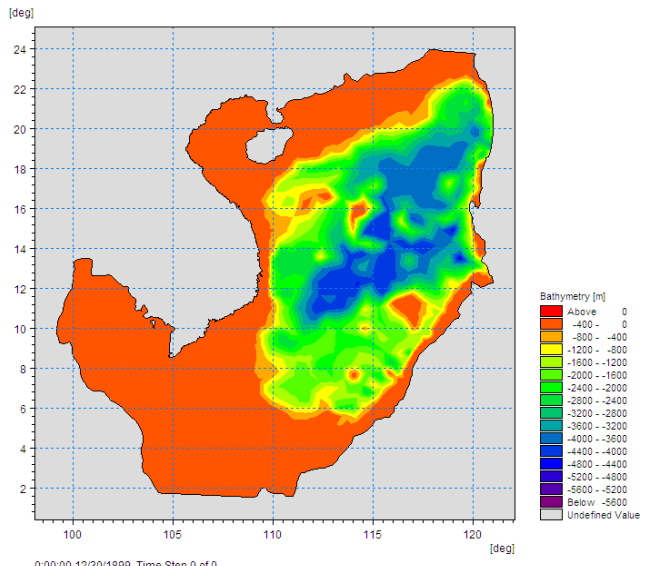

b. Bathymetry in East Sea.

Figure 3. Unstructured grid (left) and bathymetry (right) in East Sea.

The calculated area was extended to the entire East Sea extending latitudinally from $98^{\circ} \mathrm{N}$ to $122^{\circ} \mathrm{N}$ and and longitudinally from $2^{\circ} \mathrm{E}$ to $24^{\circ} \mathrm{E}$. The unstructured grid used in this work was designated containing 4014 nodes and 6830 elements. Grid resolution varies from approximately $35 \mathrm{~km}$ in the deep East Sea to less than $5 \mathrm{~km}$ in channels ensuring the detail for coastal area (Figure 3-a). The terrain in the study area was extracted from topographic at different scales ranging from 1:10,000 to 1:1,000,000 (Figure 3-b).

Wind pressure fields from 10 strong typhoons including TESS (1988), THELMA (1991), ANGELA (1992), LOLA (1993), KYLE (1993), TERESA (1994), ZACK (1995), ERNIE (1996), FAITH (1998) and LINGLING (2001) (as shown in Figure 4) were used in combination with future scenarios to simulate storm surges in the South Central coastal areas corresponding to the rare frequencies as mentioned above. 

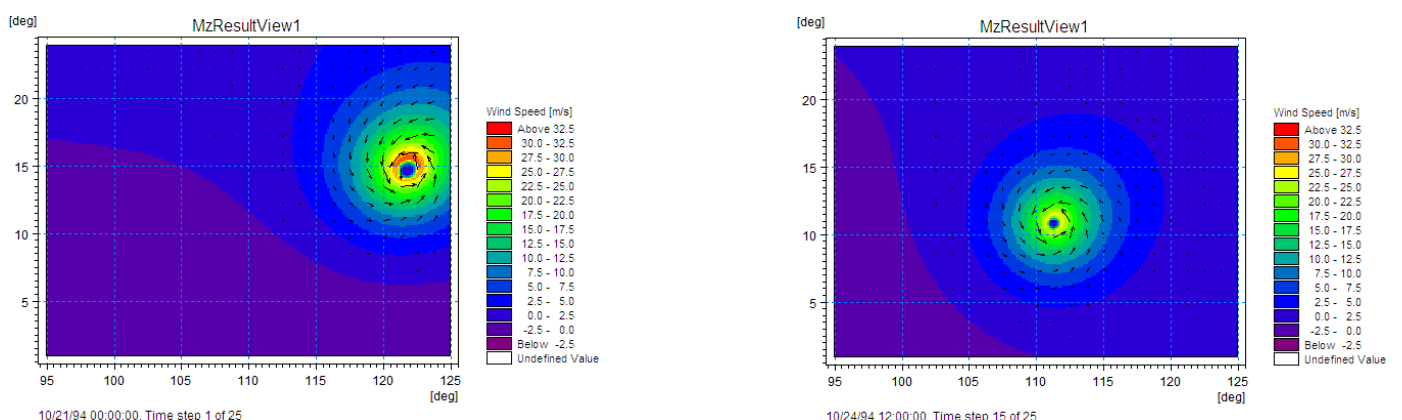

a. Wind field caused by typhoon TERESA in 1994 .
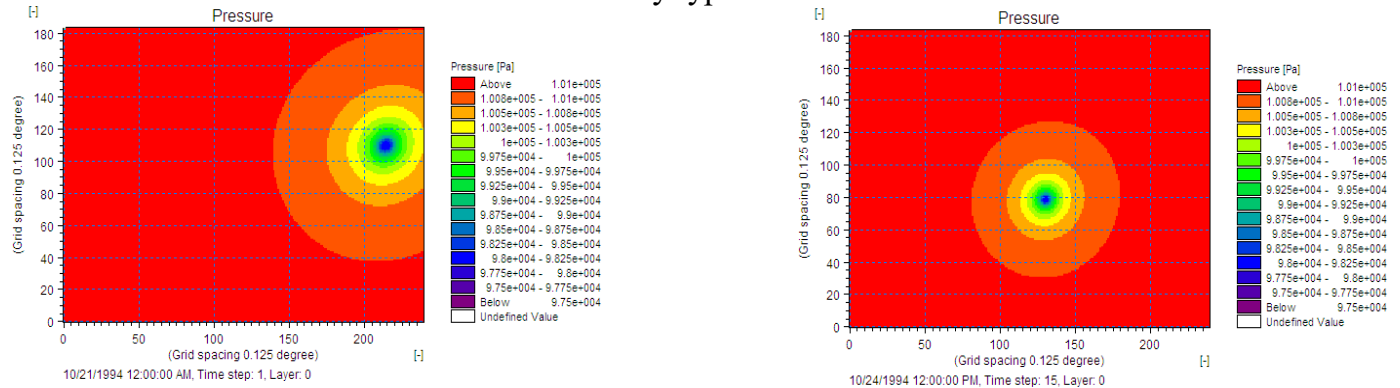

b. Pressure field caused by typhoon TERESA in 1994.
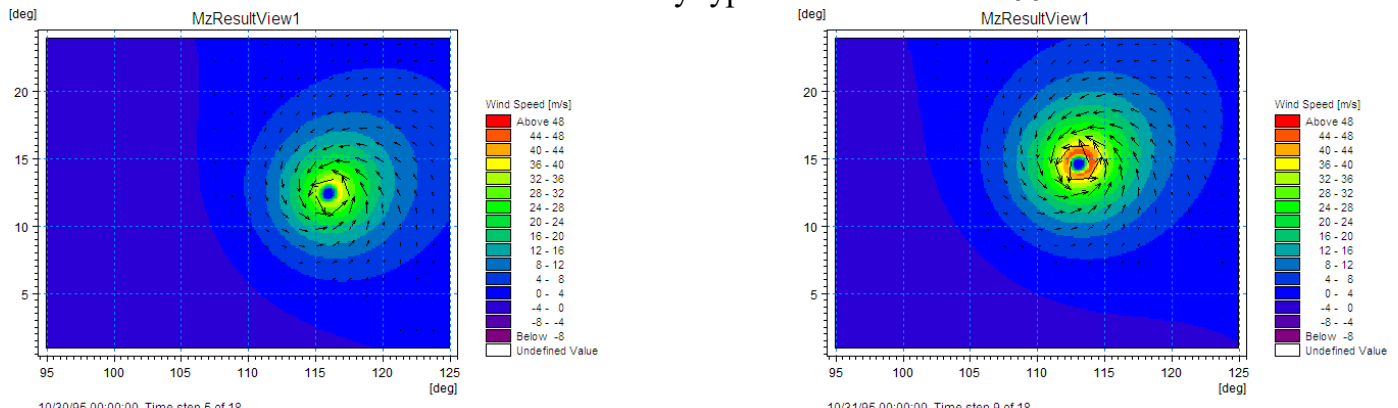

c. Wind field caused by typhoon ZACK in 1995 .
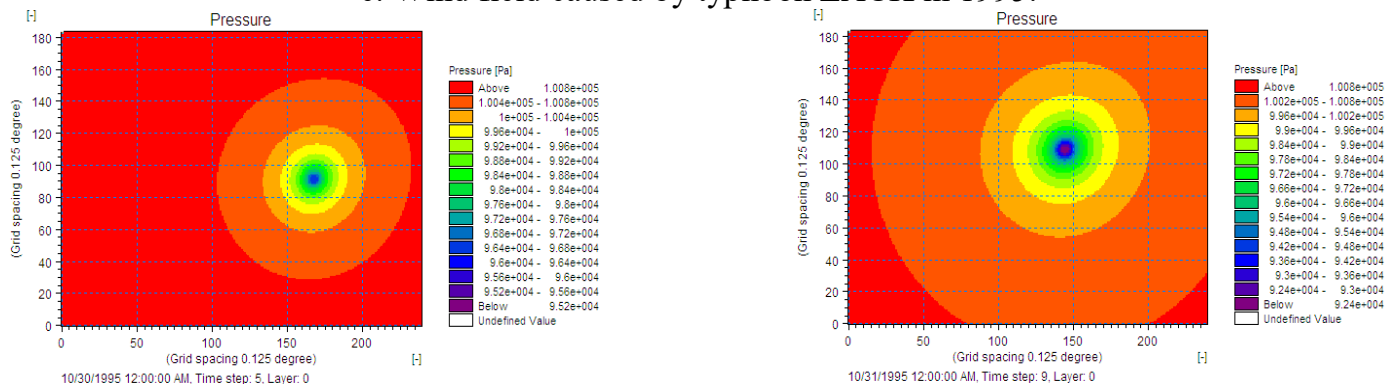

d. Pressure field caused by typhoon ZACK in 1995.

Figure 4. Wind and pressure fields caused by typhoons in 1994 and 1995.

\subsection{Model calibration and validation}

The hydraulic model was calibrated and validated using the results of the tidal harmonic analysis in January 2016 and July 2016 at Quy Nhon station. Roughness coefficient in the model is a factor that has a greater influence on the change of phase and tidal amplitude, therefore, this coefficient was adjusted to correct the reliability of the model. The roughness coefficient depends on the structure, the roughness of the bottom layer. However, there was not enough data on the bottom layer structure of the regions in the modelling area. Thus, the calculation of roughness coefficient was not feasible. In this study, roughness coefficient was divided based on different depth thresholds. The greater the depth, the smaller the coefficient of roughness and vice versa. Based on the depth field collected by survey, the roughness coefficient was calculated according to a specific depth (Figure 5). This roughness coefficient was then used for the first run of the model. 


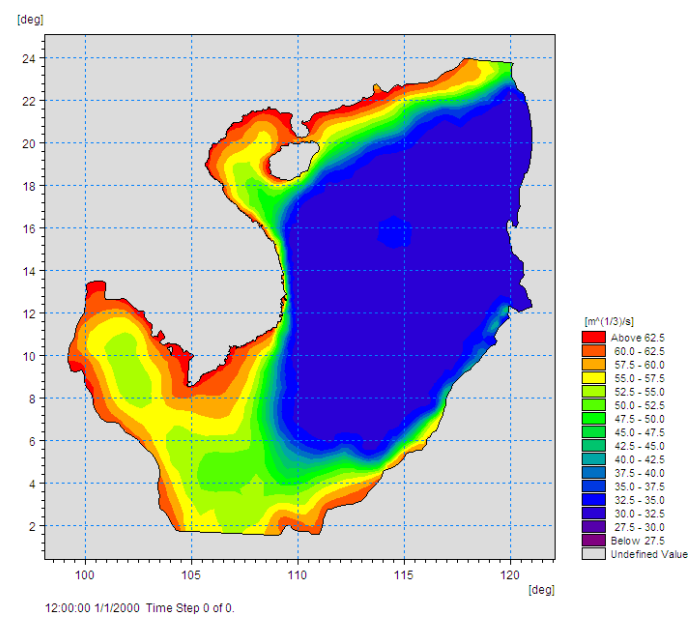

Figure 5. Distribution of Manning roughness coefficient in East Sea.

The results shows that the amplitude, phase and tidal oscillations of calculated water level were strong consistent with harmonic analysis of tidal data during the survey in both time periods (Figure 6). These results indicated the model parameters were completely reliable to simulate storm surge.
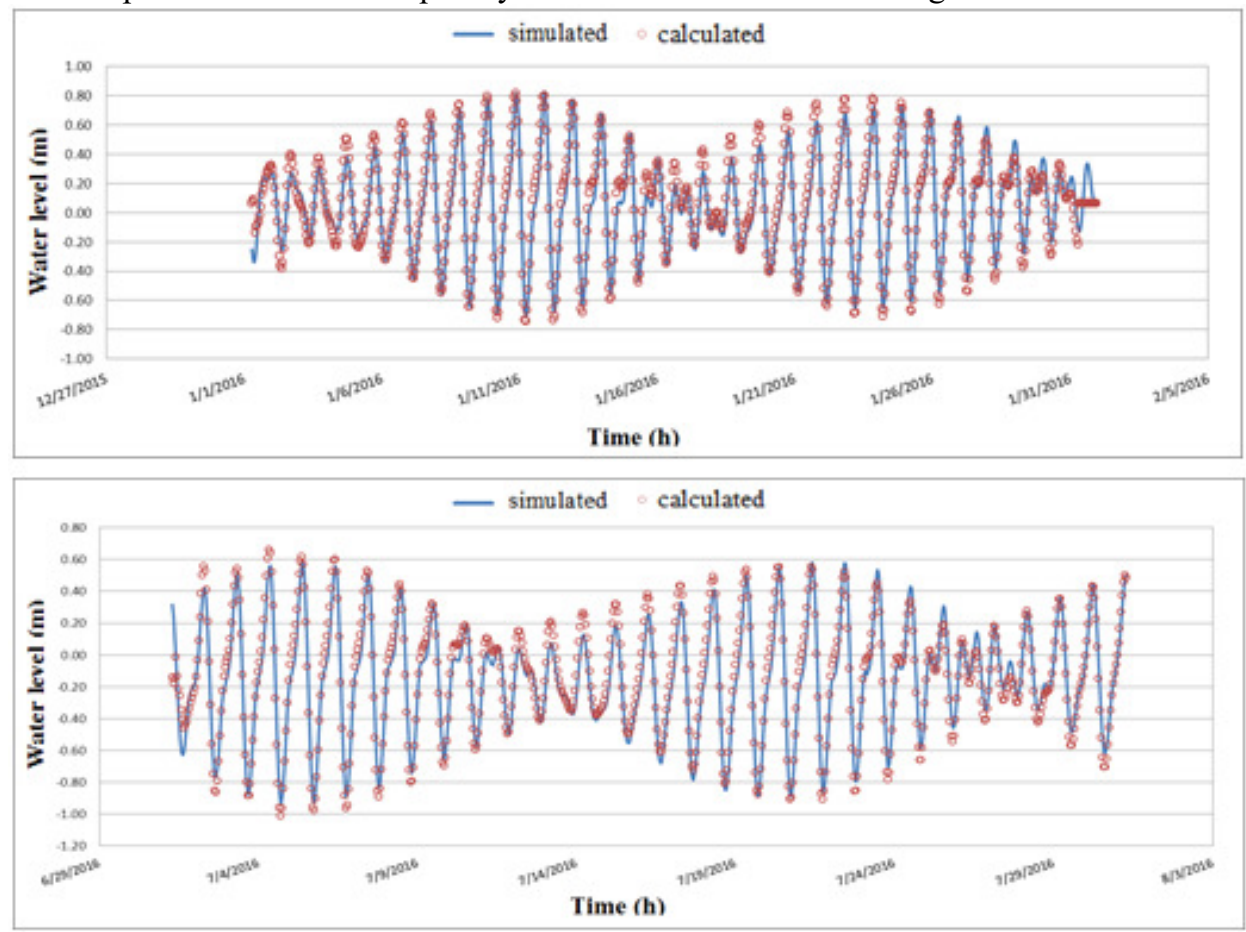

Figure 6. Comparison chart of calculated water level and harmonic analysis of tidal data at Quy Nhon station in January (upper) and July (lower) of 2016.

The storm surge model was calibrated and validated based on two typically strong storms: MIRINAE (occurred in November of 2009) and NARI (occurred in October of 2013). The calibration of storm surge model is actually the calibration of the wind friction component. Under storm conditions, the coefficient of wind friction increases due to the increase of wind speed. A set of wind friction parameters is specifically used as follows: (i) if wind velocity was lower than $7 \mathrm{~m} / \mathrm{s}$, the coefficient of wind friction is 0.001255 ; (ii) if wind velocity was higher than $20 \mathrm{~m} / \mathrm{s}$, the coefficient of wind friction was 0.0039 . The comparison results show the consistency of the phase and amplitude between the two data series collected during the two storms. The largest deviation between peaks was only about $0.1 \mathrm{~m}$ in storm MIRINAE and $0.4 \mathrm{~m}$ in storm NARI (Figure 7). Therefore, it can be concluded that the model parameters especially the wind friction coefficient were sufficiently reliable for other storms. 

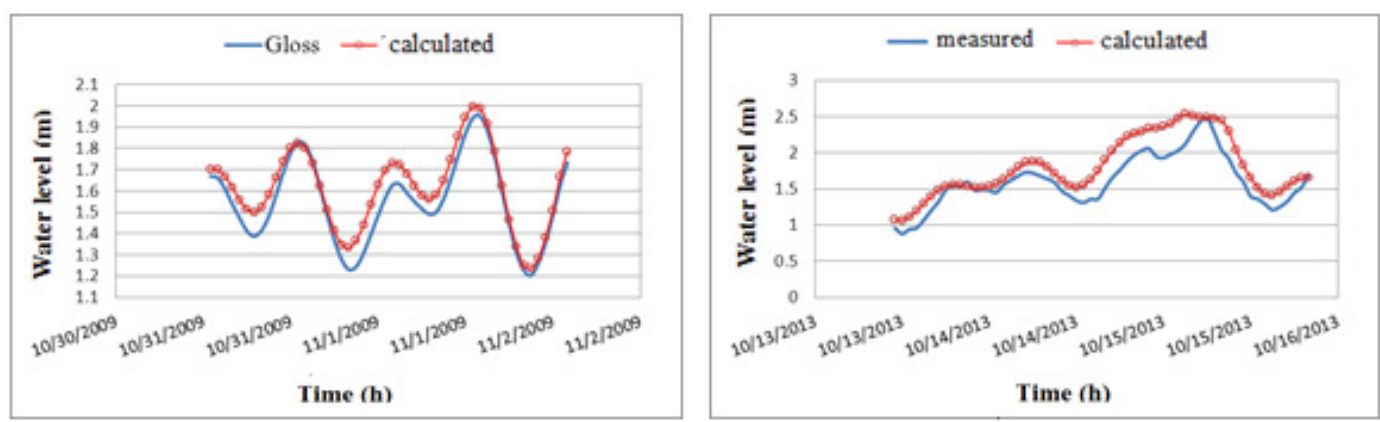

Figure 7. Comparison of calculated water level with measured data at Quy Nhon station during storm MARINAE in 2009 (left) and at Quy Nhon station during storm MARINAE in 2009 (right).

\section{Results and discussion}

Table 2. The maximum storm surges in the period 1986-2005 and in case of the rare frequency of 100 years

\begin{tabular}{|c|c|c|c|c|c|c|c|c|c|c|c|}
\hline No & $\begin{array}{l}\text { Lat. } \\
\left({ }^{\circ}\right)\end{array}$ & $\begin{array}{c}\text { Long. } \\
\left({ }^{\circ}\right)\end{array}$ & $\begin{array}{c}\mathrm{MSS}^{*} \\
(\mathrm{~m})\end{array}$ & $\begin{array}{c}\mathrm{MSS}^{* *} \\
\text { (m) }\end{array}$ & Area & No & $\begin{array}{l}\text { Lat. } \\
\left({ }^{\circ}\right)\end{array}$ & $\begin{array}{c}\text { Long. } \\
\left({ }^{\circ}\right)\end{array}$ & $\begin{array}{c}\mathrm{MSS}^{*} \\
(\mathrm{~m})\end{array}$ & $\begin{array}{c}\mathrm{MSS}^{* *} \\
(\mathrm{~m})\end{array}$ & Area \\
\hline 1 & 107.21 & 10.40 & 0.34 & 1.49 & \multirow{3}{*}{$\begin{array}{c}\text { Ba Ria } \\
\text {-Vung } \\
\text { Tau }\end{array}$} & 17 & 109.22 & 13.73 & 1.06 & 1.13 & \multirow{7}{*}{$\begin{array}{l}\text { Binh } \\
\text { Dinh }\end{array}$} \\
\hline 2 & 107.36 & 10.46 & 0.36 & 1.68 & & 18 & 109.23 & 13.77 & 1.04 & 1.05 & \\
\hline 3 & 107.48 & 10.50 & 0.38 & 1.80 & & 19 & 109.25 & 13.94 & 1.06 & 1.07 & \\
\hline 4 & 107.85 & 10.71 & 0.41 & 1.47 & \multirow{6}{*}{$\begin{array}{l}\text { Binh } \\
\text { Thuan }\end{array}$} & 20 & 109.21 & 14.09 & 1.19 & 1.08 & \\
\hline 5 & 107.90 & 10.72 & 0.41 & 1.38 & & 21 & 109.18 & 14.20 & 1.22 & 1.05 & \\
\hline 6 & 108.08 & 10.91 & 0.46 & 2.34 & & 22 & 109.14 & 14.35 & 1.50 & 1.21 & \\
\hline 7 & 108.36 & 11.02 & 0.47 & 1.98 & & 23 & 109.07 & 14.55 & 1.36 & 1.20 & \\
\hline 8 & 108.54 & 11.16 & 0.47 & 1.82 & & 24 & 109.06 & 14.64 & 1.31 & 1.20 & \multirow{5}{*}{$\begin{array}{c}\text { Quang } \\
\text { Ngai }\end{array}$} \\
\hline 9 & 108.75 & 11.27 & 0.48 & 1.66 & & 25 & 109.00 & 14.83 & 1.47 & 1.40 & \\
\hline 10 & 109.04 & 11.58 & 0.68 & 1.12 & $\begin{array}{l}\text { Ninh } \\
\text { Thuan }\end{array}$ & 26 & 108.92 & 14.99 & 1.64 & 1.45 & \\
\hline 11 & 109.12 & 11.90 & 0.61 & 1.27 & \multirow{4}{*}{$\begin{array}{c}\text { Khanh } \\
\text { Hoa }\end{array}$} & 27 & 108.90 & 15.18 & 1.42 & 1.41 & \\
\hline 12 & 109.17 & 12.43 & 1.71 & 2.04 & & 28 & 108.87 & 15.28 & 1.77 & 1.49 & \\
\hline 13 & 109.34 & 12.77 & 1.10 & 1.48 & & 29 & 108.71 & 15.42 & 2.05 & 1.93 & \multirow{3}{*}{$\begin{array}{c}\text { Quang } \\
\text { Nam }\end{array}$} \\
\hline 14 & 109.36 & 12.82 & 0.83 & 0.78 & & 30 & 108.56 & 15.58 & 1.95 & 1.98 & \\
\hline 15 & 109.29 & 13.15 & 0.97 & 1.00 & \multirow{2}{*}{$\begin{array}{l}\text { Phu } \\
\text { Yen }\end{array}$} & 31 & 108.42 & 15.82 & 1.68 & 1.89 & \\
\hline 16 & 109.24 & 13.48 & 0.88 & 1.33 & & 32 & 108.28 & 15.99 & 1.60 & 2.19 & $\begin{array}{c}\mathrm{Da} \\
\text { Nang }\end{array}$ \\
\hline
\end{tabular}

Notes: Lat. and Long. are latitude and longitude; $\mathrm{MSS}^{*}$ and $\mathrm{MSS}^{* *}$ are the maximum storm surges in period of 1986-2005 and of the rare 100-year frequency corresponding to scenarios in 2100, relatively. 


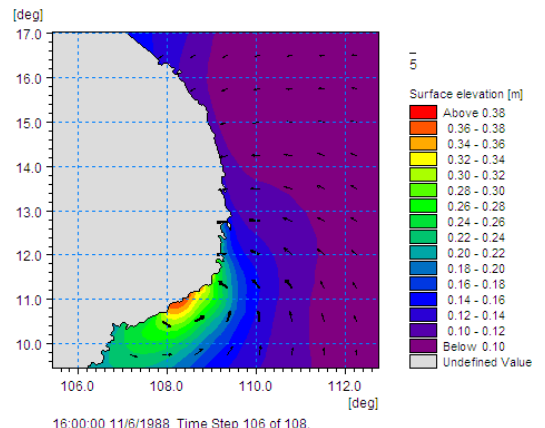

Storm surge in 1988 storm TESS

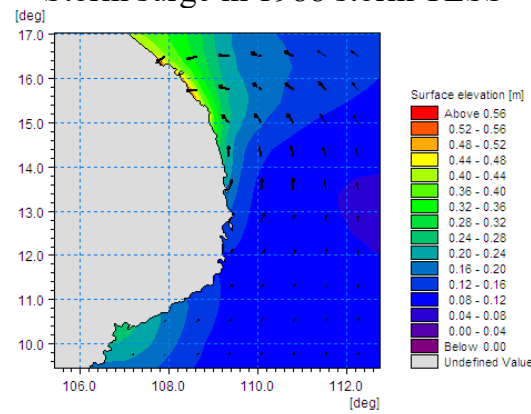

torm surge in 1992 storm ANGELA

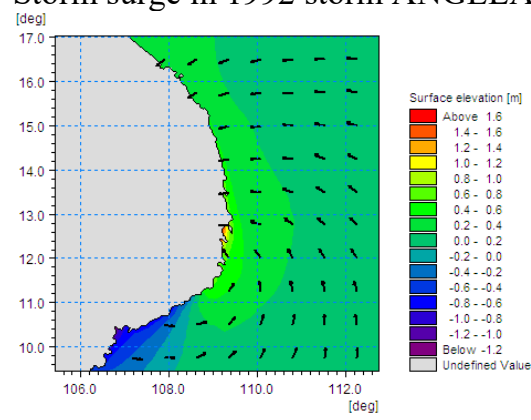

Storm surge in 1993 storm LOLA

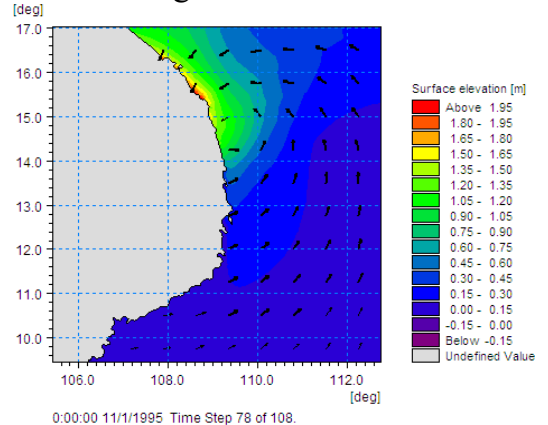

Storm surge in 1995 storm ZACK

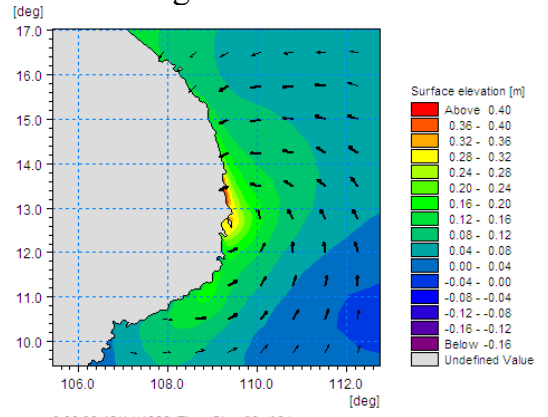

Storm surge in 1998 storm FAITH

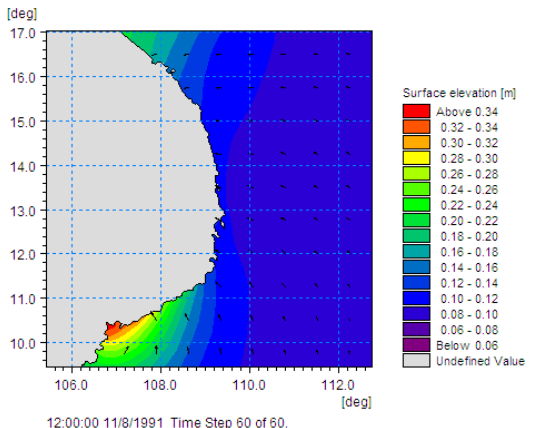

Storm surge in 1991 storm THELMA

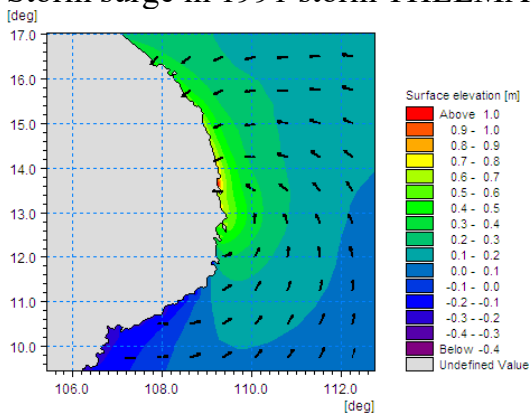

Storm surge in 1993 storm KYLE

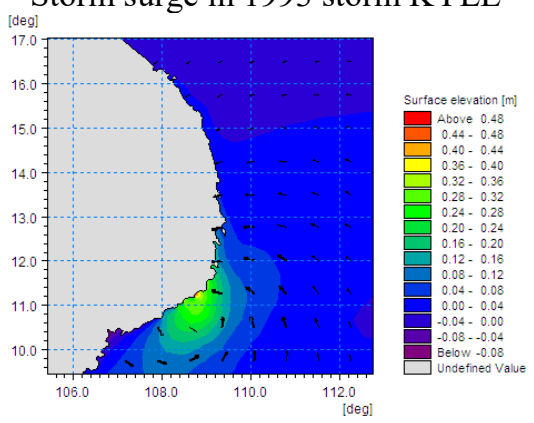

$0: 00: 00$ 10/26/1994 Time Step 126 of 150

Storm surge in 1994 storm TERESA

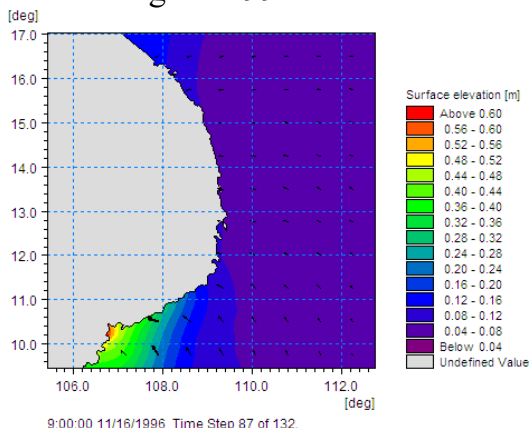

Storm surge in 1996 storm ERNIE

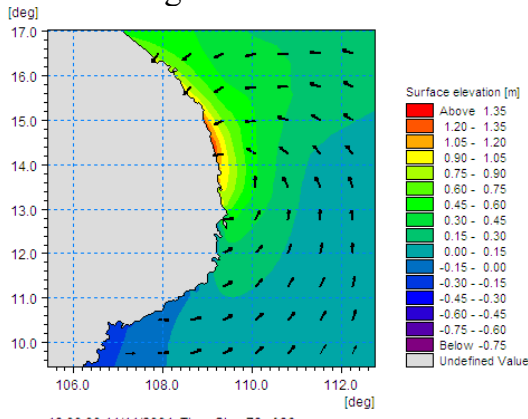

Storm surge in 2001 storm LINGLING Figure 8. Storm surges in 10 strong storms in the 1986-2005 period. 
Storm surges in 10 typical storms in the 1986-2005 period were shown in Figure 8. The detailed calculation results at 32 points along the coastal areas in the South Central region were summarised in Table 2. Simulation results from Figure 9-left show that the most affected area by storm surges was the area from Phu Yen to Da Nang with a rise of up to $2 \mathrm{~m}$ in Quang Nam, approximately $1.8 \mathrm{~m}$ in Quang Ngai province and about $1.5 \mathrm{~m}$ in Phu Yen province during period of 1986-2005. The least affected area was found in the coastal areas of Ba Ria-Vung Tau with the largest increase of $0.4 \mathrm{~m}$. Medium-low storm surges were detected in the coastal areas in Binh Thuan (ranging from $0.41 \mathrm{~m}$ to $0.48 \mathrm{~m}$ ), Phu Yen (from $0.88 \mathrm{~m}$ to $0.97 \mathrm{~m}$ ). Medium-high storm surges were found in the coastal areas of Khanh Hoa (from $0.61 \mathrm{~m}$ to $1.71 \mathrm{~m}$ ), Binh Dinh (from $1.04 \mathrm{~m}$ to $1.5 \mathrm{~m}$ ), Quang Ngai (from $1.31 \mathrm{~m}$ to $1.77 \mathrm{~m}$ ) and Quang Nam (from $1.68 \mathrm{~m}$ to $2.05 \mathrm{~m}$ ). In general, to a certain extent, the coastal areas in the South Central region of Vietnam were strongly affected by storm surges.

Simulation results of storm surges for 100-year frequency were statistically summarised in Table 2 and shown in Figure 9-right. Data from Figure 9 shows that the maximum storm surge were found in Binh Thuan province with an increase of about $2.34 \mathrm{~m}$; the minimum storm surge was in Khanh Hoa province with the water level rise of about $0.78 \mathrm{~m}$. The high storm surges were detected in the coastal areas of Da Nang, Quang Nam, Quang Ngai, Khanh Hoa and the southern coast of Ninh Thuan. Relatively low storm surges occurred mainly in coastal areas of Quang Ngai, Binh Dinh and Phu Yen and Ninh Thuan.
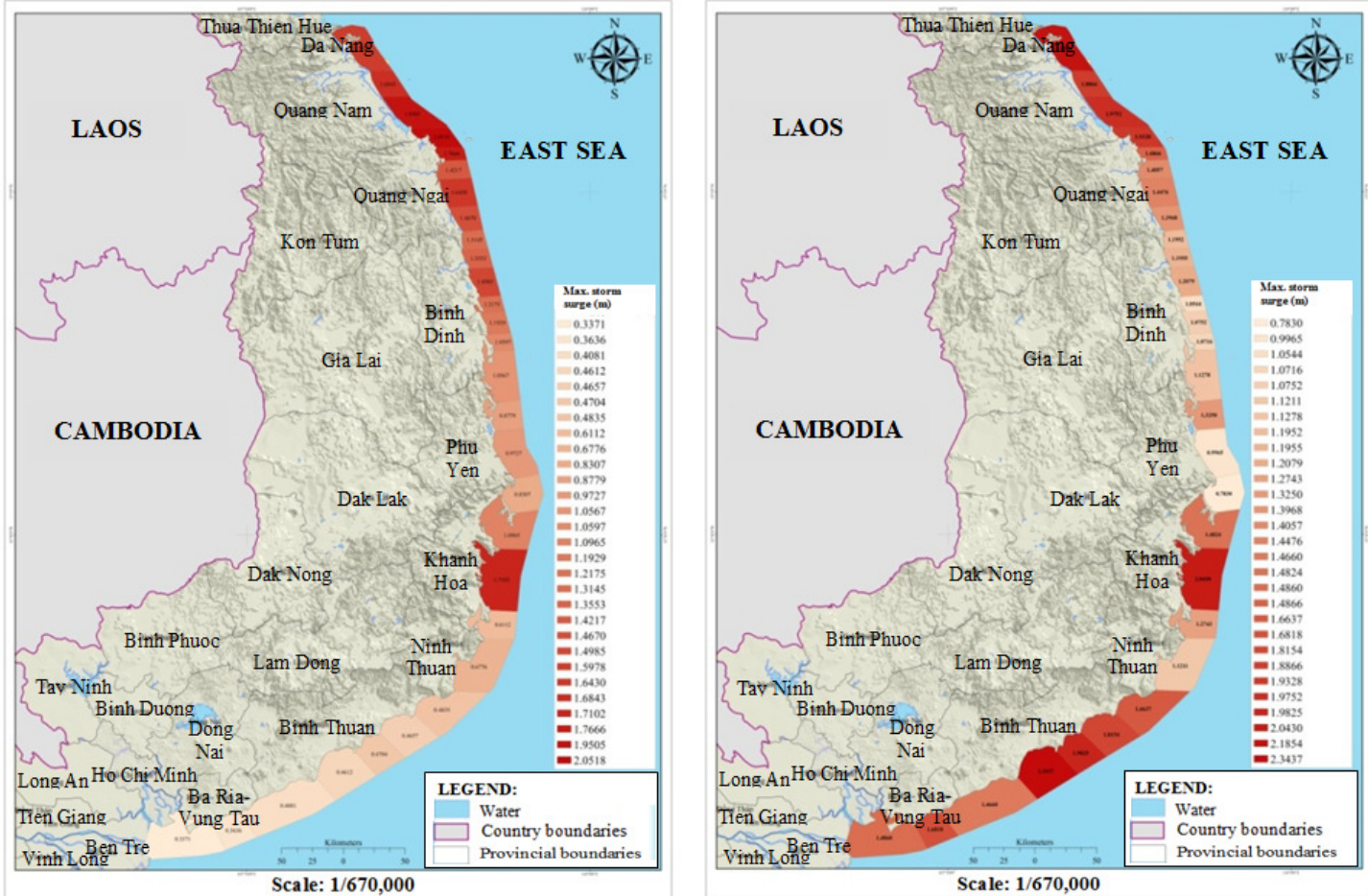

Figure 9. Map of the maximum storm surges in the 1986-2005 period (left) and in case of the rare 100-year frequency corresponding to scenarios in 2100 (right) in the South Central Coast of Vietnam.

\section{Conclusions}

In this study, storm surges were simulated in the South Central coast of Vietnam under climate change using the Mike 21-FM model. Wind pressure fields were derived from in the 1986-2005 period. Wind pressure fields of typical storms were first identified in period of 1986-2005 using the parametric wind field model. Storm surge risk was then simulated based on the rare 10, 50 and 100-year frequency corresponding to 2030, 2050, and 2100 scenarios. Storm surge simulation parameters were calibrated and validated by the survey data collected in the November 2009 Typhoon Mirinae and October 2013 Typhoon Nari. The study results show the maximum and minimum storm surge of $2.34 \mathrm{~m}$ and 0.78 were detected in the coastal areas of Binh Thuan province and Khanh Hoa province, respectively. This study demonstrated the Mike 21-FM is an effective model to simulate storm surges under climate change in the coastal areas.

\section{References}

Afentoulis, V., Eleftheria, K., Eleni, S., Evangelos, M., Archontia, L., Christos, M. \& Vasiliki, T. (2017) Coastal Processes Assessment Under Extreme Storm Events Using Numerical Modelling Approaches. Environmental Processes, 4(3), 731-747.

Bode, L. \& Hardy, T. A. (1997) Progress and recent developments in storm surge modeling. Journal of Hydraulic 
Engineering, 123(4), 315-331.

Bruneau, N., Grieser, J., Loridan, T., Bellone, E. \& Khare, S. (2017) The impact of extra-tropical transitioning on storm surge and waves in catastrophe risk modelling: application to the Japanese coastline. Natural Hazards, $85(2), 649-667$.

Casulli, V. \& Cheng, R. T. (1992) Semi-implicit finite difference methods for three-dimensional shallow water flow. International Journal for numerical methods in fluids, 15(6), 629-648.

Guo, Y., Zhang, J., Zhang, L. \& Shen, Y. (2009) Computational investigation of typhoon-induced storm surge in Hangzhou Bay, China. Estuarine, Coastal and Shelf Science, 85(4), 530-536.

Houston, S. H., Shaffer, W. A., Powell, M. D. \& Chen, J. (1999) Comparisons of HRD and SLOSH surface wind fields in hurricanes: Implications for storm surge modeling. Weather and Forecasting, 14(5), 671-686.

Hu, R., Fang, F., Salinas, P., Pain, C., Domingo, N. S. \& Mark, O. (2019) Numerical simulation of floods from multiple sources using an adaptive anisotropic unstructured mesh method. Advances in Water Resources, 123, $173-188$

Hubbert, G. D. \& Mclnnes, K. L. (1999) A storm surge inundation model for coastal planning and impact studies. Journal of Coastal Research, 168-185.

Imamura, F. \& Van To, D. (1997) Flood and typhoon disasters in Viet Nam in the half century since 1950. Natural Hazards, 15(1), 71-87.

Jiang, X., Mori, N., Tatano, H., Yang, L. \& Shibutani, Y. (2016) Estimation of property loss and business interruption loss caused by storm surge inundation due to climate change: a case of Typhoon Vera revisit. Natural Hazards, 84(1), 35-49.

Karim, M. F. \& Mimura, N. (2008) Impacts of climate change and sea-level rise on cyclonic storm surge floods in Bangladesh. Global Environmental Change, 18(3), 490-500.

Li, M., Wu, W., Wang, J., Che, Z. \& Xie, Y. (2017) Simulating and mapping the risk of surge floods in multiple typhoon scenarios: a case study of Yuhuan County, Zhejiang Province, China. Stochastic environmental research and risk assessment, 31(3), 645-659.

McInnes, K. L., Hubbert, G. D., Abbs, D. J. \& Oliver, S. E. (2002) A numerical modelling study of coastal flooding. Meteorology and Atmospheric Physics, 80(1-4), 217-233.

Mohit, M., Yamashiro, M., Hashimoto, N., Mia, M., Ide, Y. \& Kodama, M. (2018) Impact Assessment of a Major River Basin in Bangladesh on Storm Surge Simulation. Journal of Marine Science and Engineering, 6(3), 99.

Morey, S. L., Baig, S., Bourassa, M. A., Dukhovskoy, D. S. \& O'Brien, J. J. (2006) Remote forcing contribution to storm-induced sea level rise during Hurricane Dennis. Geophysical Research Letters, 33(19).

Musinguzi, A., Akbar, M. K., Fleming, J. G. \& Hargrove, S. K. (2019) Understanding Hurricane Storm Surge Generation and Propagation Using a Forecasting Model, Forecast Advisories and Best Track in a Wind Model, and Observed Data-Case Study Hurricane Rita. Journal of Marine Science and Engineering, 7(3), 77.

Neumann, J., Emanuel, K., Ravela, S., Ludwig, L. \& Verly, C. (2015) Risks of coastal storm surge and the effect of sea level rise in the Red River Delta, Vietnam. Sustainability, 7(6), 6553-6572.

Nguyen, H. N., Vu, K. T. \& Nguyen, X. N. (2007) Flooding in Mekong River Delta, Viet Nam. Human development report, 2008, 23.

Pan, Z. \& Liu, H. (2015) Numerical study of typhoon-induced storm surge in the Yangtze estuary of China using a coupled 3D model. Procedia Engineering, 116, 849-854.

Patro, S., Chatterjee, C., Mohanty, S., Singh, R. \& Raghuwanshi, N. (2009) Flood inundation modeling using MIKE FLOOD and remote sensing data. Journal of the Indian Society of Remote Sensing, 37(1), 107-118.

Pattanayak, S., Mohanty, U. \& Rao, A. (2016) Simulation of storm surges in the bay of Bengal using one-way coupling between NMM-WRF and IITD storm surge model. Marine Geodesy, 39(5), 376-400.

Schmidt-Thome, P., Nguyen, T. H., Pham, T. L., Jarva, J. \& Nuottimäki, K. (2015) Climate change in Vietnam, Climate Change Adaptation Measures in VietnamSpringer, 7-15.

Schmitt, K., Albers, T., Pham, T. \& Dinh, S. (2013) Site-specific and integrated adaptation to climate change in the coastal mangrove zone of Soc Trang Province, Viet Nam. Journal of Coastal Conservation, 17(3), 545558

Sheng, Y., Alymov, V., Paramygin, V. \& Davis, J. (2006) An integrated modeling system for forecasting of storm surge and coastal inundation. Estuarine and coastal modeling IX, 585-602.

Sheng, Y. P., Zhang, Y. \& Paramygin, V. A. (2010) Simulation of storm surge, wave, and coastal inundation in the Northeastern Gulf of Mexico region during Hurricane Ivan in 2004. Ocean Modelling, 35(4), 314-331.

Takagi, H., Nguyen, D., Esteban, M., Tran, T., Knaepen, H. L. \& Mikami, T. (2012) Vulnerability of coastal areas in Southern Vietnam against tropical cyclones and storm surges, The 4th International Conference on Estuaries and Coasts (ICEC2012).

Takagi, H., Thao, N. D. \& Esteban, M. (2014) Tropical cyclones and storm surges in southern Vietnam, Coastal Disasters and Climate Change in VietnamElsevier, 3-16.

Thai, T. H., Tri, D. Q. \& Hoang, D. V. (2018) Research on The Affected Simulation of Waves and Storm Surge 
In Coastal Central Vietnam. Journal of Hydro - Meteorology(3), 15.

Wang, Q., Zhong, S., Li, X., Zhan, C., Wang, X. \& Liu, P. (2016) Supratidal land use change and its morphodynamic effects along the eastern coast of Laizhou Bay during the recent 50 years. Journal of Coastal Research, 74(sp1), 83-94.

Yan, B., Li, S., Wang, J., Ge, Z. \& Zhang, L. (2016) Socio-economic vulnerability of the megacity of Shanghai (China) to sea-level rise and associated storm surges. Regional environmental change, 16(5), 1443-1456.

Young, I. \& Sobey, R. (1981) The numerical prediction of tropical cyclone wind-wavesDepartment of Civil \& Systems Engineering, James Cook University of North Queensland. 